\title{
Impact of preoperative and postoperative atrial fibrillation on outcome after mitral valvuloplasty for nonischemic mitral regurgitation
}

Ko Bando, MD, ${ }^{a}$ Hitoshi Kasegawa, MD, ${ }^{\text {e }}$ Yukikatsu Okada, MD, ${ }^{d}$ Junjiro Kobayashi, MD, ${ }^{a}$ Akiko Kada, MPH, ${ }^{\mathrm{c}}$ Tomoki Shimokawa, MD, ${ }^{\text {e }}$ Michinori Nasu, MD, ${ }^{d}$ Satoshi Nakatani, MD, ${ }^{b}$ Kazuo Niwaya, MD, ${ }^{a}$ Osamu Tagusari, MD, Hiroyuki Nakajima, MD, ${ }^{d}$ Mitsuhiro Hirata, MD, ${ }^{f}$ Toshikatsu Yagihara, MD, and Soichiro Kitamura, MD ${ }^{a}$

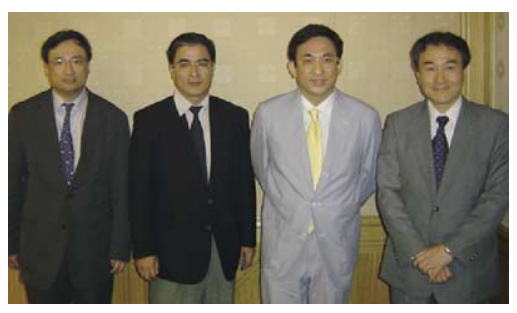

Kobayashi, Okada, Bando, Kasegawa (left to right)

Objective: We sought to determine the impact of preoperative or postoperative atrial fibrillation on survival, stroke, and cardiac function after mitral valvuloplasty for mitral regurgitation.

Methods: Between 1991 and 2003, 1026 patients with nonischemic/noncardiomyopathy mitral valve regurgitation underwent mitral valve plasty in 3 centers; 663 patients remained in sinus rhythm (group A), and 363 patients had atrial fibrillation or flutter preoperatively (group B) with concomitant maze procedures (group BM, $\mathrm{n}=163$ ) or without maze procedures (group $\mathrm{BN}, \mathrm{n}=200$ ).

Results: Eight-year freedom from cardiovascular-related death was better in group A $(99.3 \%)$ than group B (BM: 96.9\%, BN: 81.6\%) $(P<.001)$ and also better in group BM than group BN $(P=.007)$. The adjusted hazard ratio of group $\mathrm{B}$ versus group A for preoperative differences was 5.1 (95\% confidence interval: 1.8-14.8). Eight-year freedom from stroke was better in group A (99.2\%) than group B (BM: 98.2\%, BN: 82.6\%) $(P<.001)$ and also better in group BM than group BN $(P<$ $.001)$. Patients with preoperative atrial fibrillation had larger left atria and left ventricular systolic dimensions. The adjunct maze procedure improved left ventricular systolic dimensions over mitral repair alone (group A vs B: $P=.359$; group BM vs BN: $P=.001)$.

From the Departments of Cardiovascular Surgery, ${ }^{\mathrm{a}}$ Cardiology, ${ }^{\mathrm{b}}$ and Biostatistics, ${ }^{\mathrm{c}}$ National Cardiovascular Center, Osaka, Japan; Department of Cardiothoracic Surgery, ${ }^{\mathrm{d}}$ Kobe City General Hospital, Kobe, Japan; Department of Cardiovascular Surgery, ${ }^{\text {e }}$ Sakakibara Heart Institute, Tokyo, Japan and Kitasato University Medical School, ${ }^{\mathrm{f}}$ Kanagawa, Japan.

Read at the Eighty-fourth Annual Meeting of The American Association for Thoracic Surgery, Toronto, Ontario, Canada, April 25-28, 2004.

Received for publication May 11, 2004; revisions received Oct 17, 2004; accepted for publication Oct 28, 2004.

Address for reprints: Ko Bando, MD, Department of Cardiovascular Surgery, National Cardiovascular Center, 5-7-1, Fujishirodai, Suita, Osaka, 565-8565, Japan (E-mail:kobando@hsp.ncvc.go.jp)

J Thorac Cardiovasc Surg 2005;129: 1032-40

$0022-5223 / \$ 30.00$

Copyright (C) 2005 by The American Association for Thoracic Surgery

doi:10.1016/j.jtcvs.2004.10.037

Conclusion: Preoperative permanent/persistent atrial fibrillation was associated with a dilated left atrium and reduced left ventricular function in patients with mitral regurgitation. Including the maze procedure with mitral repair improved survival, late cardiac function, and freedom from late stroke.

$\mathrm{O}$ ptimal timing of mitral valve repair for patients with chronic mitral regurgitation is critical and remains controversial. ${ }^{1}$ Current American Heart Association/Americal College of Cardiology guidelines for surgery have focused on the onset of symptoms and left ventricular dysfunction. ${ }^{2}$ However, waiting until a patient is in New York Heart Association (NYHA) class III or for a reduction of ventricular ejection fraction may result in increased postoperative morbidity and mortality. ${ }^{3}$

Atrial fibrillation (AF) commonly accompanies mitral regurgitation and has been identified as an independent predictor of overall survival and late stroke after surgery for mitral regurgitation. ${ }^{4}$ However, there are conflicting reports regarding the impact of AF on late outcome after mitral valve surgery. ${ }^{5,6}$ Moreover, little is known regarding the influence of preoperative and postoperative AF on survival and late cardiac function after mitral valve repair.

Recent studies indicated that combining the maze procedure and mitral valve repair reduces the incidence of late stroke, ${ }^{7,8}$ but the impact of an adjunct maze procedure on 
late survival and cardiac function remains unclear. The purpose of this study was to determine the impact of preoperative and postoperative $\mathrm{AF}$ on survival, cardiovascular-related deaths, stroke, and cardiac function after mitral valve repair for nonischemic mitral regurgitation.

\section{Patients and Methods}

Between January 1991 and December 2003, 1026 consecutive patients underwent mitral valve repair at 3 centers: National Cardiovascular Center $(\mathrm{n}=332)$, Sakakibara Heart Institute $(\mathrm{n}=$ 379), and Kobe Central City Hospital $(n=315)$. Thirty-three patients who were initially planned to undergo mitral valve repair but instead underwent mitral valve replacement at initial surgery were excluded from the study. We reviewed data from the operative notes, clinical case histories, and laboratory investigations, including electrocardiograms, echocardiograms, and cardiac catheterization reports. Institutional review board approval for this study was obtained in each institution. Follow-up data were collected from each institution's outpatient records and correspondence with referring physicians. Follow-up data for more than 6 months after operation were available in all patients. The mean follow-up period was 4.3 years, and 8 patients were lost to follow-up within 5 years. Morbid events were analyzed for both the early (in hospital) and late (after discharge) periods.

\section{Definitions}

Preoperative AF was defined as permanent/persistent/paroxysmal AF according to American Heart Association/Americal College of Cardiology guidelines. ${ }^{9}$ Preoperative stroke was defined as cerebral thromboembolism diagnosed by a neurologist and confirmed by computed tomography scan and was clearly differentiated from transient ischemic attack. Transient ischemic attacks were not counted as strokes in this study. Causes of death were divided as all cause of deaths and cardiovascular-related deaths. Cardiovascular-related deaths included death from congestive heart failure, arrhythmia, cerebral infarction, cerebral bleeding, and other cardiovascular-related events. We chose to analyze the recurrence of arrhythmia after the first 30 days because early postoperative AF might be caused by different mechanisms than those of permanent/persistent AF. Electrocardiography was performed in each patient within the first 30 days, 6 months after surgery, and at the annual clinic visit of referring physicians or surgeons.

\section{Patients}

Demographic data and preoperative cardiac information are given in Table 1. The patients were divided into groups as follows: 663 patients in sinus rhythm (group A) and 363 patients in permanent $\mathrm{AF}(\mathrm{n}=310)$, persistent $\mathrm{AF}(\mathrm{n}=28)$, recurrent paroxysmal AF $(\mathrm{n}$ $=15)$, or atrial flutter $(\mathrm{n}=10)$ preoperatively (group $\mathrm{B}$ ). In group $\mathrm{B}$, a concomitant maze procedure was performed in 163 patients (group BM), whereas the remaining 200 patients (group BN) did not undergo a maze procedure because of the surgeon's preference (eg, the maze procedure was omitted in complex mitral vale repair or severe congestive heart failure), documented duration of $\mathrm{AF}$ ( $>20$ years), or emergency surgery.
TABLE 1. Preoperative clinical characteristics

\begin{tabular}{|c|c|c|c|c|}
\hline & $\begin{array}{c}A \\
(n=663)\end{array}$ & $\begin{array}{c}\text { BM } \\
(n=163)\end{array}$ & $\begin{array}{c}\text { BN } \\
(n=200)\end{array}$ & $P$ value \\
\hline Gender (male/female) & $396 / 267$ & $109 / 54$ & $129 / 71$ & .166 \\
\hline Age (y) (range/median) & $18-82 / 56$ & $22-79 / 60$ & $19-78 / 62$ & $<.001$ \\
\hline Hypertension & $58(9 \%)$ & $9(6 \%)$ & $29(15 \%)$ & .009 \\
\hline Diabetes & $15(2 \%)$ & $1(1 \%)$ & $6(3 \%)$ & .278 \\
\hline Stroke history & $19(3 \%)$ & $8(5 \%)$ & $13(7 \%)$ & .051 \\
\hline Renal failure & $5(1 \%)$ & $1(1 \%)$ & $2(1 \%)$ & .910 \\
\hline LA thrombus & $8(1 \%)$ & $5(3 \%)$ & $0(0 \%)$ & .033 \\
\hline \multicolumn{5}{|l|}{ NYHA class } \\
\hline I & $69(10 \%)$ & $10(6 \%)$ & $14(7 \%)$ & $<.001$ \\
\hline II & $369(56 \%)$ & $79(49 \%)$ & $88(44 \%)$ & \\
\hline III & $160(24 \%)$ & $54(33 \%)$ & $77(39 \%)$ & \\
\hline IV & $36(5 \%)$ & $13(8 \%)$ & $15(8 \%)$ & \\
\hline Unknown & $29(4 \%)$ & $7(4 \%)$ & $6(3 \%)$ & \\
\hline \multicolumn{5}{|l|}{ LAD } \\
\hline$<60 \mathrm{~mm}$ & $579(87 \%)$ & $82(50 \%)$ & $137(69 \%)$ & $<.001$ \\
\hline$\geq 60 \mathrm{~mm}$ & $16(2 \%)$ & $72(44 \%)$ & $58(29 \%)$ & \\
\hline Unknown & $68(10 \%)$ & $9(6 \%)$ & $5(3 \%)$ & \\
\hline \multicolumn{5}{|l|}{ LVDs } \\
\hline$<40 \mathrm{~mm}$ & $439(66 \%)$ & $76(47 \%)$ & $108(54 \%)$ & $<.001$ \\
\hline$\geq 40 \mathrm{~mm}$ & $152(23 \%)$ & $70(43 \%)$ & $86(43 \%)$ & \\
\hline Unknown & $72(11 \%)$ & $17(10 \%)$ & $6(3 \%)$ & \\
\hline \multicolumn{5}{|l|}{$\%$ FS } \\
\hline$<25 \%$ & $24(4 \%)$ & $24(15 \%)$ & $31(16 \%)$ & $<.001$ \\
\hline$\geq 25 \%$ & $573(86 \%)$ & $130(80 \%)$ & $164(82 \%)$ & \\
\hline Unknown & $66(10 \%)$ & $9(6 \%)$ & $5(3 \%)$ & \\
\hline
\end{tabular}

LA, Left atrial; NYHA, New York Heart Association; $L A D$, left atrial dimension; $L V D$, left ventricular dimension; $F S$, fractional shortening.

\section{Surgical Indications and Techniques}

Table 2 summarizes the surgical pathology of the mitral valve. Ischemic mitral regurgitation and dilatated cardiomyopathy were excluded from this study. Although combined tricuspid valve surgery and atrial or ventricular septal defect closure were included, patients who underwent combined coronary artery bypass, aortic valve surgery, or aortic surgery were excluded from the study.

Repair of the mitral valve was performed by techniques described by Carpentier ${ }^{10}$ and David and colleagues. ${ }^{11}$ Prolapse of the mid-scallop of the posterior leaflet was corrected by resection; prolapse of the anterior leaflet was corrected by chordal replacement with polytetrafluoroethylene (Gore-Tex; W. L. Gore and Associates, Inc, Flagstaff, Ariz) sutures. ${ }^{10,11}$ Commissural prolapse was repaired by resection and sutures with or without the Kay technique. Patients with longstanding mitral regurgitation and dilated mitral annulus underwent annuloplasty with Carpentier, Duran, or Cosgrove rings, or a handmade ring made by autologous pericardium. ${ }^{12}$ In patients undergoing the maze procedure, 3 different techniques were used: Cox maze III $(n=18)$, Kosakai maze $(\mathrm{n}=47)$, and cryo-maze procedure $(\mathrm{n}=98) ; 5$ patients in atrial flutter underwent only the right side of the cryo-maze procedure. The cryo-maze procedure was modified from the Kosakai maze procedure to use cryoablation around the left pulmonary veins, avoiding the incision encircling all 4 orifices of the pulmonary veins. $^{8,13}$ 
TABLE 2. Surgical pathology and concomitant surgery

\begin{tabular}{|c|c|c|c|c|}
\hline & $\begin{array}{c}A \\
(n=663)\end{array}$ & $\begin{array}{c}\text { BM } \\
(n=163)\end{array}$ & $\begin{array}{c}\text { BN } \\
(n=200)\end{array}$ & $\begin{array}{c}P \\
\text { value }\end{array}$ \\
\hline \multicolumn{5}{|l|}{ Cause } \\
\hline Degenerative & $492(74 \%)$ & $111(68 \%)$ & $161(81 \%)$ & $<.001$ \\
\hline Infective endocarditis & $127(19 \%)$ & $8(5 \%)$ & $18(9 \%)$ & \\
\hline Rheumatic & $24(4 \%)$ & $30(18 \%)$ & $18(9 \%)$ & \\
\hline Congenital & $20(3 \%)$ & $14(9 \%)$ & $3(2 \%)$ & \\
\hline \multicolumn{5}{|l|}{ Anterior leaflet involved } \\
\hline Yes & $265(40 \%)$ & $49(30 \%)$ & $97(49 \%)$ & .002 \\
\hline No & $398(60 \%)$ & $114(70 \%)$ & $103(52 \%)$ & \\
\hline \multicolumn{5}{|l|}{ Concomitant surgery } \\
\hline TAP & $48(7 \%)$ & $48(29 \%)$ & $59(30 \%)$ & $<.001$ \\
\hline ASD/VSD repair & $17(3 \%)$ & $13(8 \%)$ & $3(2 \%)$ & .001 \\
\hline \multicolumn{5}{|l|}{ Year of operation } \\
\hline $1991-1995$ & $170(26 \%)$ & $42(26 \%)$ & $49(25 \%)$ & .263 \\
\hline $1996-2000$ & $287(43 \%)$ & $73(45 \%)$ & $110(55 \%)$ & \\
\hline $2001-2003$ & $206(31 \%)$ & $48(29 \%)$ & $41(21 \%)$ & \\
\hline
\end{tabular}

$\overline{T A P}$, tricuspid annuloplasty; $A S D$, atrial septal defect; $V S D$, ventricular septal defect.

\section{Preoperative and Postoperative Echocardiograph Evaluation}

Transthoracic echocardiograms were performed before surgery, at discharge, and annually thereafter. In the majority of the patients, intraoperative echocardiography was performed at the completion of the surgery. Successful mitral valve repair was defined as a maximal mitral regurgitant area less than $2 \mathrm{~cm} .^{2,14}$ Postoperative echocardiographic examinations were performed during a follow-up period of $4.3 \pm 3.2$ years after operation. For those patients who died or underwent reoperation during the follow-up period, the last echocardiographic data before death or the secondary surgical intervention were used. ${ }^{13}$

\section{Postoperative Anticoagulation}

All patients were given warfarin sodium for the first 3 postoperative months. Permanent anticoagulation was recommended if AF persisted after operation. In case autologous pericardium was used as a ring annuloplasty, systemic anticoagulation was not performed for patients in sinus rhythm.

\section{Statistics}

All values were expressed as mean \pm SD or percentages. The $\chi^{2}$ or Kruskal-Wallis test was used for comparison. The adjusted hazard ratio (HR) of group B versus group A for death and stroke was estimated by using a Cox proportional hazard model with variables: gender; age; hypertension; diabetes; stroke history; NYHA class; preoperative left atrial dimension (LAD) $(<60 \mathrm{~mm} / \geq 60 \mathrm{~mm})$; preoperative left ventricular dimension (LVD) $(<40 \mathrm{~mm} / \geq 40 \mathrm{~mm})$; years of operation; rheumatic, degenerative, infective endocarditis; anterior leaflet involved; and institution. To estimate the adjusted $\mathrm{HR}$ of group $\mathrm{BN}$ against BM, the propensity score $^{15}$ was used in the Cox proportional hazard model. The propensity score (the probability of the maze procedure was combined with that of mitral valve repair in patients with $\mathrm{AF}$ ) was estimated by multivariable logistic regression by use of the same variables in the Cox proportional hazard model. Survival and freedom from stroke and AF were estimated by using the Kaplan-Meier method. Survival curves were compared with the log-rank test. Echocardiographic variables were compared by $t$ test as percentage changes from preoperation to last follow-up.

\section{Results}

Patient Background and Surgical Techniques

Patient characteristics among the 3 cohorts are shown in Table 1. Patients in group A were younger and had better NYHA functional class, smaller LAD, and smaller left ventricular systolic dimension (LVDs) when compared with those with preoperative AF (groups BN and BM). Furthermore, patients with infective endocarditis were more likely to be in sinus rhythm, whereas rheumatic patients had a higher incidence of AF before surgery. Among patients with preoperative $\mathrm{AF}$, the use of a concomitant maze procedure was significantly less when anterior leaflet repair was involved. Finally, concomitant tricuspid valve surgery was required more frequently in groups $\mathrm{BN}$ and $\mathrm{BM}$ than group A (Table 2).

\section{Postoperative Morbidity and Mortality}

Hospital death occurred in 15 patients (1.5\%); the causes of deaths included respiratory failure $(n=6)$, congestive heart failure $(n=4)$, multisystem organ failure $(n=3)$, and others $(\mathrm{n}=2)$. Postoperative complications included bleeding (15), respiratory failure (13), renal failure (6), infection (5), low output syndrome (5), cerebral infarction (4), myocardial infarction (3), left ventricular rupture (3), and liver failure (1).

\section{Freedom from Reoperation and Durability of Mitral Valve Repair}

Only 22 patients (3.3\%) in group A, 9 patients (4.5\%) in group $\mathrm{BN}$, and 7 patients $(4.3 \%)$ in group $\mathrm{BM}$ required reoperation (Appendix 1). Moreover, only 4\% to $9 \%$ of patients had more than moderate regurgitation in the latest follow-up over 2 years after surgery (Appendix 2).

\section{Survival and Late Mortality}

All patients were followed for at least 6 months after operation. Actuarial survival of group B was significantly lower than group A, and survival of group BN was significantly lower than group BM (Figure 1). Eight-year survivals were 99.3\% (A), 96.9\% (BM), and 81.6\% (BN). Similar trends were observed in freedom from cardiovascular-related deaths (Figure 2).

There were 46 late deaths. The causes of late deaths included cerebral infarction (14), congestive heart failure (8), malignancy (8), cerebral bleeding (4), respiratory failure (2), multisystem organ failure $(\mathrm{n}=1)$, and others (9). Of note, 12 patients remained in $\mathrm{AF}$ or had frequent paroxysmal AF after surgery and died of thromboembolic events. 


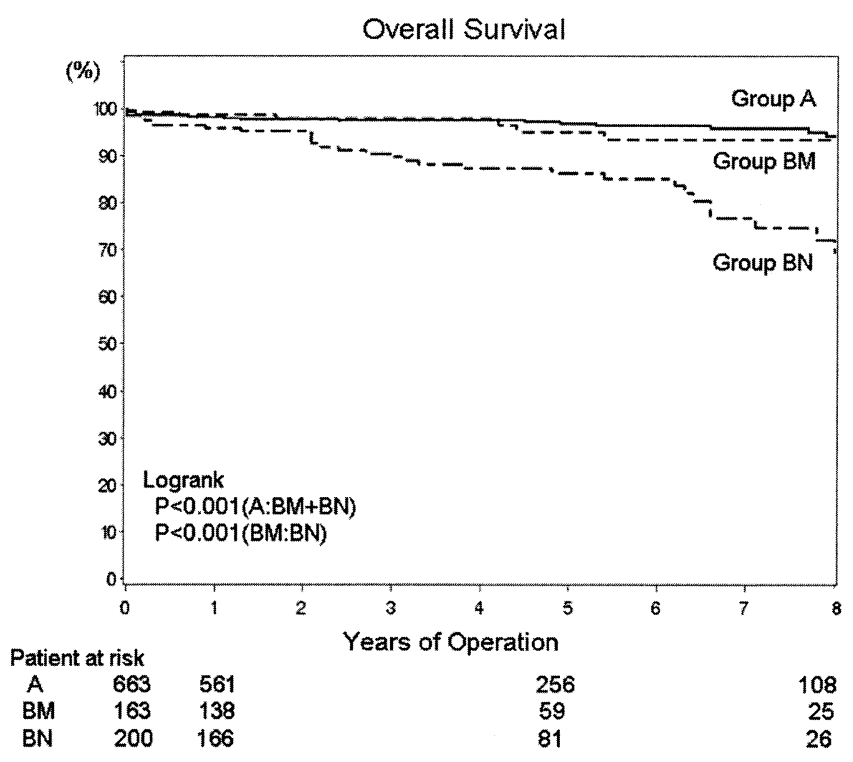

Figure 1. Overall survival.

Because significant background variability was observed among the groups, the Cox hazard model was applied to analyze the independent risk factors. The adjusted HR of cardiovascular-related deaths for group B versus group A was 5.1 (95\% confidence interval [CI]: 1.8-14.8). The risk for late mortality increased with advanced age (HR: 2.5, 95\% CI: 1.4-4.3, 10-year unit) and a preoperative enlarged LAD (HR: 3.3, 95\% CI: 1.2-9.0) (Table 3), although the adjusted $\mathrm{HR}$ of group $\mathrm{BN}$ versus group BM did not reach a significant level (HR: 2.7, 95\% CI: 0.4-18.0).

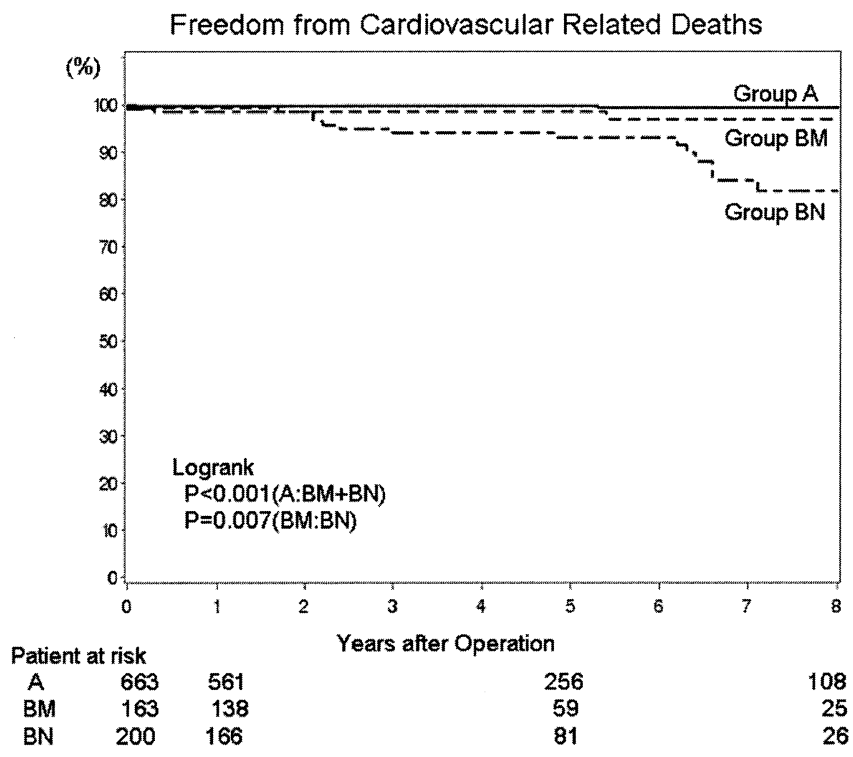

Figure 2. Freedom from cardiovascular-related deaths.
TABLE 3. Results of Cox analysis for cardiac-related death

\begin{tabular}{lccc}
\hline Variables* $^{*}$ & Hazard ratio & $\mathbf{9 5 \% ~ C l}$ & $\boldsymbol{P}$ value \\
\hline Group B vs A & 5.12 & $1.77-14.80$ & .003 \\
Age & 2.48 & $1.44-4.27$ & .001 \\
NYHA (I, II/III, IV) & 2.10 & $0.84-5.23$ & .114 \\
Preoperative LAD & 3.34 & $1.24-8.99$ & .017 \\
$\quad$ ( $<60 \mathrm{~mm} / \geq 60 \mathrm{~mm})$ & & & \\
Infective endocarditis & 3.03 & $0.58-15.78$ & .189 \\
Institution A vs C & 3.48 & $1.01-11.97$ & .049 \\
$\quad$ B vs C & 3.33 & $1.01-11.03$ & .049 \\
Group BN vs BM† & 2.73 & $0.41-18.01$ & .298
\end{tabular}

$C l$, Confidence interval; NYHA, New York Heart Association; $L A D$, left atrial dimension. *Variables with $P$ value $<.20$ were presented. $\dagger$ Adjusted by propensity score for maze procedure.

\section{Incidence of Stroke After Mitral Valve Repair}

Twenty-six patients had a late stroke, 23 of whom were aged more than 60 years. Eight-year freedom from stroke was better in group A (99.2\%) compared with group B (BM: 98.2\%, BN: 82.6\%, $P<.001$ ) (Figure 3).

The adjusted HR of stroke incidence for group B versus group A was 8.7 (95\% CI: 2.7-27.9). Risk for late mortality increased with advanced age (HR: 3.4, 95\% CI: 1.9-6.4, 10-year unit) (Table 4). For group BN versus group BM, the HR was significantly higher at 7.6 (95\% CI: 1.2-47.7).

\section{Recurrence of AF}

We chose to analyze recurrence of arrhythmia after the first 30 days because early postoperative AF might be caused by different mechanisms than those of permanent/persistent AF. In patients with preoperative sinus rhythm (group A), $94.2 \%(92.4 \%-96.1 \%)$ of patients maintained sinus rhythm

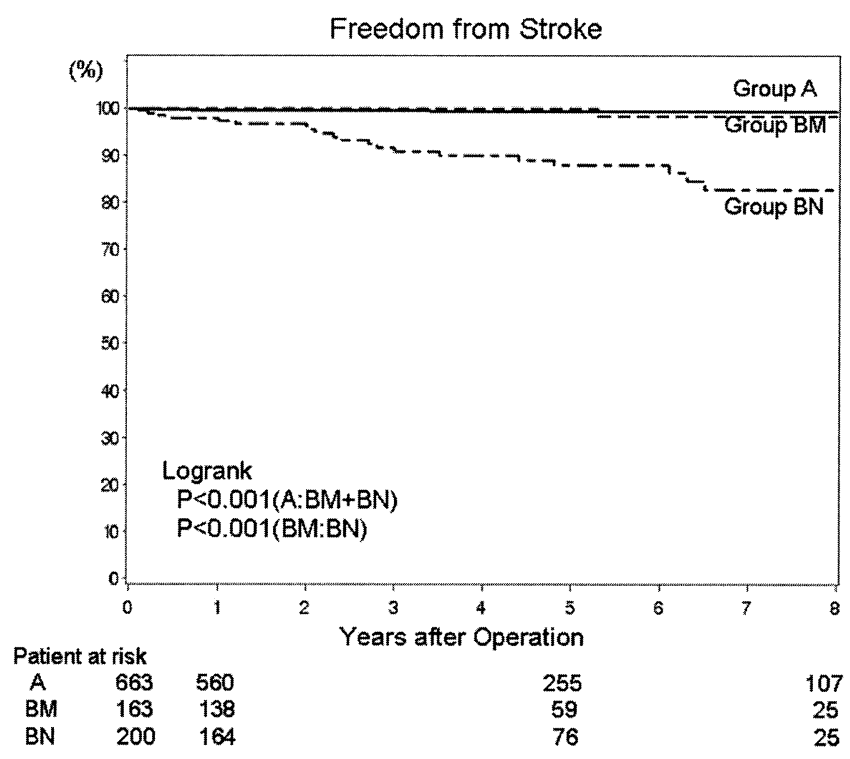

Figure 3. Freedom from stroke. 
TABLE 4. Results of Cox analysis for stroke

\begin{tabular}{lccr}
\hline Variables* & Hazard ratio & 95\% Cl & P value \\
\hline Group B vs A & 8.69 & $2.71-27.89$ & $<.001$ \\
Age & 3.37 & $1.85-6.13$ & $<.001$ \\
Preoperative LAD & 2.24 & $0.79-6.34$ & .129 \\
$\begin{array}{l}\text { ( }<60 \mathrm{~mm} / \geq 60 \mathrm{~mm}) \\
\text { Preoperative LVDs }\end{array}$ & 0.47 & $0.17-1.25$ & .129 \\
(<40 mm/ $\geq 40 \mathrm{~mm}$ ) & & & \\
Institution A vs C & 1.27 & $0.32-5.11$ & .736 \\
$\quad$ B vs C & 2.84 & $0.88-9.18$ & .082 \\
Group BN vs BM $\dagger$ & 7.63 & $1.22-47.66$ & .030 \\
\hline
\end{tabular}

$C$, Confidence interval; $L A D$, left atrial dimension; $L V D$, left ventricular dimension. *Variables with $P$ value $<.20$ were presented. $†$ Adjusted by propensity score for maze procedure.

8 years after surgery. In patients who underwent a concomitant maze procedure for preoperative $\mathrm{AF}$ (group $\mathrm{BM}$ ), freedom from $\mathrm{AF}$ at 8 years was $80.4 \%$ (72.4\%-88.3\%). Freedom from AF in the group undergoing mitral valvuloplasty alone (group BN) at 8 years was $24.3 \%$ (18.1\%$30.5 \%$ ) (Figure 4).

\section{Impact of Postoperative AF on Late Mortality and}

\section{Stroke}

Because the incidence of postoperative AF was different among the 3 groups, freedom from cardiac-related death and stroke was analyzed separately by postoperative rhythm 1 month after surgery.

In regard to the impact of postoperative rhythm, freedom from cardiac-related death in patients with postoperative regular rhythm was $98.9 \%$ (97.9\%-100\%) compared with $82.1 \%$ in those with permanent/persistent

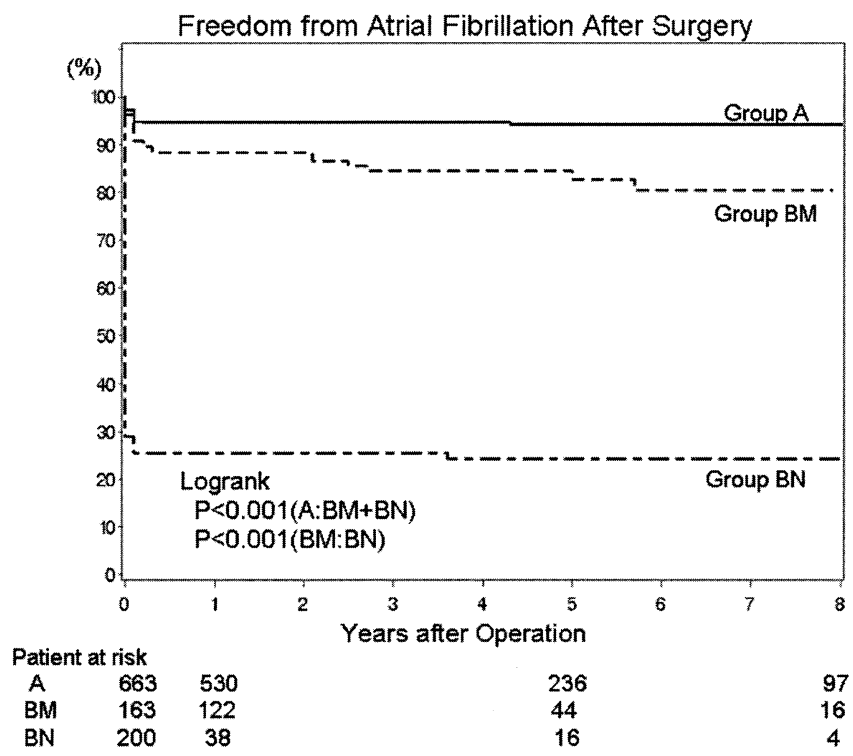

Figure 4. Freedom from atrial fibrillation after surgery.

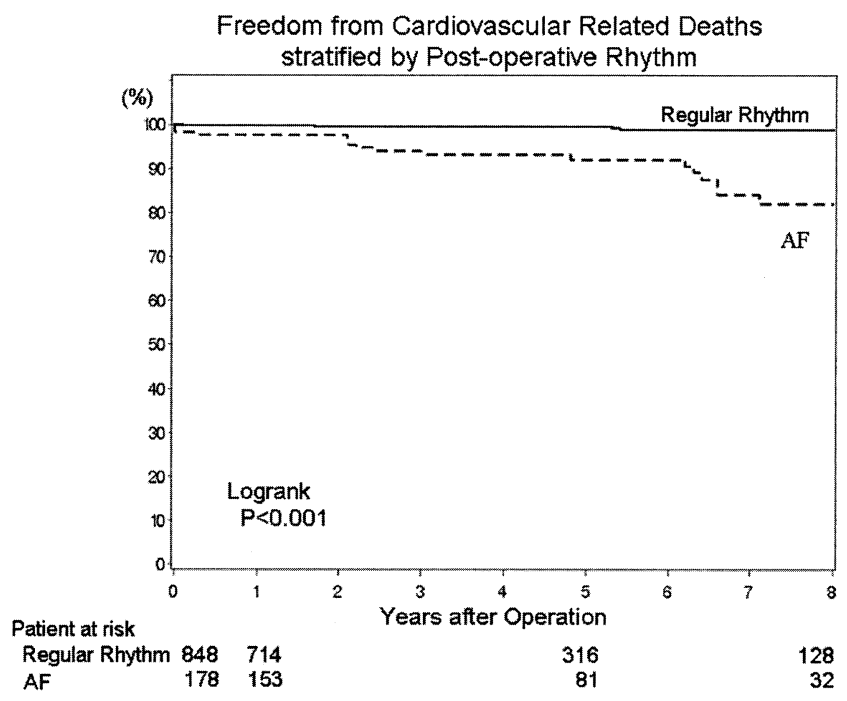

Figure 5. Freedom from cardiovascular-related deaths stratified by postoperative rhythm. AF, Atrial fibrillation.

AF (73.5\%-90.7\%) (Figure 5). Freedom from stroke in patients with postoperative regular rhythm was $99.4 \%$ (98.7\%-100\%) compared with 81.0\% (73.2\%-88.7\%) in those withpba permanent/persistent AF after surgery (Figure 6). The summary of stroke- and cardiac-related deaths stratified by postoperative AF is depicted in Appendix 3 .

\section{Comparison of Preoperative and Postoperative}

Echocardiographic Variables

Before surgery, patients with permanent/persistent AF had a larger LAD than patients in sinus rhythm (group A: $45.7 \pm$

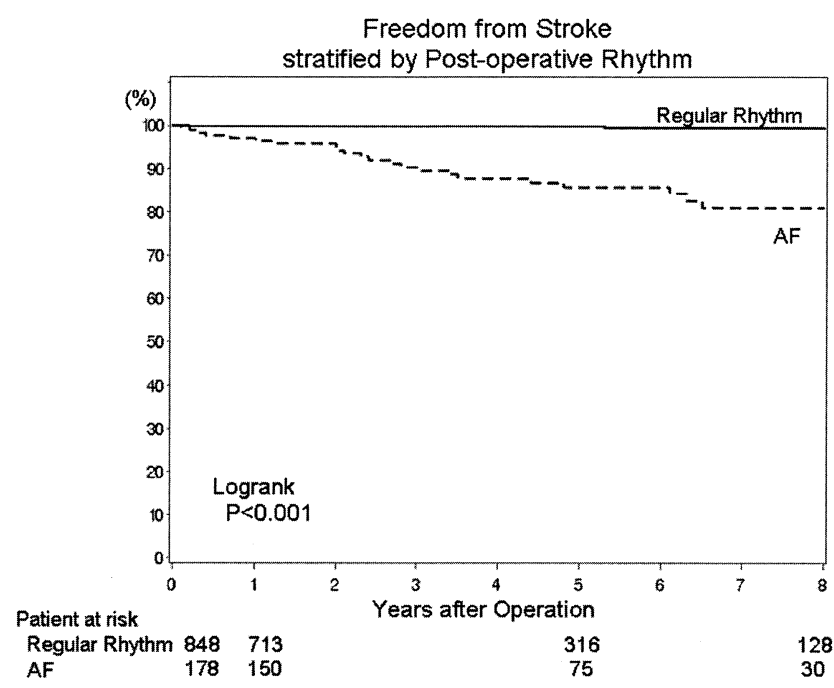

Figure 6. Freedom from stroke stratified by postoperative rhythm. $A F$, Atrial fibrillation.

1036 The Journal of Thoracic and Cardiovascular Surgery • May 2005 
TABLE 5. Echocardiographic variables

\begin{tabular}{|c|c|c|c|c|c|}
\hline \multirow[b]{2}{*}{ Variables } & \multirow[b]{2}{*}{ Preoperative } & \multirow{2}{*}{$\begin{array}{c}\text { Discharge } \\
\text { percentage change }\end{array}$} & \multirow{2}{*}{$\begin{array}{c}\text { Last follow-up } \\
\text { percentage change }\end{array}$} & \multicolumn{2}{|c|}{$P$ value } \\
\hline & & & & $A: B M+B N$ & BM:BN \\
\hline \multicolumn{6}{|l|}{ LAD (mm) } \\
\hline Group A & $45.7 \pm 7.2(595)$ & $-17.0 \pm 14.0(470)$ & $-11.3 \pm 15.3(313)$ & .001 & \\
\hline Group BM & $57.8 \pm 8.2(154)$ & $-20.9 \pm 11.4(79)$ & $-23.3 \pm 12.6(122)$ & & $<.001$ \\
\hline Group BN & $53.9 \pm 10.7(195)$ & $-18.8 \pm 14.6(178)$ & $-7.1 \pm 127.8(105)$ & & \\
\hline \multicolumn{6}{|l|}{ LVDd (mm) } \\
\hline Group A & $57.3 \pm 7.5(596)$ & $-17.7 \pm 10.5(492)$ & $-15.5 \pm 13.7(311)$ & .006 & \\
\hline Group BM & $58.6 \pm 9.5(146)$ & $-12.6 \pm 12.7(75)$ & $-11.5 \pm 16.0(102)$ & & .574 \\
\hline Group BN & $58.9 \pm 7.6(194)$ & $-14.2 \pm 12.2(180)$ & $-12.6 \pm 12.4(102)$ & & \\
\hline \multicolumn{6}{|l|}{ LVDs (mm) } \\
\hline Group A & $36.0 \pm 6.9(591)$ & $-7.0 \pm 17.4(485)$ & $-15.0 \pm 17.1(310)$ & .359 & \\
\hline Group BM & $39.1 \pm 7.8(146)$ & $-4.3 \pm 16.3(73)$ & $-17.9 \pm 17.8(102)$ & & .001 \\
\hline Group BN & $39.1 \pm 7.8(194)$ & $-6.2 \pm 19.8(178)$ & $-9.1 \pm 19.6(102)$ & & \\
\hline
\end{tabular}

Number of patients is given in parentheses. $L A D$, Left atrial dimension; $L V D d$, Left ventricular end-diastolic dimension; $L V D s$, Left ventricular end-systolic dimension.

$7.2 \mathrm{~mm}$; group BM: $57.8 \pm 8.2 \mathrm{~mm}$; group BN: $53.9 \pm 10.7$ $\mathrm{mm})$. After surgical intervention, the LAD size decreased but enlarged again in patients with permanent/persistent AF after surgery (Table 5). Similarly, left ventricular end-diastolic dimension and LVDs decreased after mitral repair in all groups. However, in patients who did not undergo a maze procedure (group $\mathrm{BN}$ ), late recurrent enlargement of LAD was observed, whereas LAD remained small in groups $A$ and BM late after surgery ( $>2$ years). Furthermore, a significant improvement of LVDs was observed in group BM compared with BN.

\section{Discussion}

In the current study, we elucidated the impact of preoperative and postoperative $\mathrm{AF}$ and an adjunct maze procedure on late survival, stroke, and change in echocardiographic indices after mitral valvuloplasty.

This multicenter retrospective study suggests that mitral valve repair before development of AF may have a significantly positive impact on survival and freedom from stroke and improved late cardiac function after surgical intervention. Before surgery, patients in group A generally had smaller LAD and LVDs compared with group B. Accordingly, patients in group A had excellent 8-year freedom from cardiovascular-related death $(99.3 \%)$ and freedom from stroke (99.2\%). In contrast, patients with preoperative AF (group B) had significantly lower freedom from cardiovascular-related deaths (BM: 96.9\%, BN: 81.6\%) and stroke (BM: $98.2 \%$, BN: $82.6 \%$ ) 8 years after surgery. Group BM (with adjunct maze procedure) showed similar high freedom from cardiovascular-related death $(96.9 \%)$ and stroke (98.2\%) compared with group A. Thus, the maze procedure may help to improve survival and reduce the incidence of stroke when combined with mitral valve repair as previously reported. ${ }^{16,17}$
Because significant differences were observed in patient demographics and clinical history, the risk factors for late death and stroke were analyzed with the Cox hazard model. Preoperative AF, advanced age, and larger LAD predicted cardiovascular-related mortality late after surgery (Table 3 ). When groups BM and BN were compared, however, the effect of the maze procedure on survival was not significant when the propensity score was used (Table 3). Preoperative AF and older age were the significant risk factors for late stroke after mitral valve repair. The effect of the maze procedure in reducing the incidence of stroke was confirmed by the Cox hazard model with the propensity score (Table 4). These results suggest that advanced age and omission of the maze procedure in patients with AF are the independent risk factors for stroke after mitral valve repair.

Because 27 patients in group BM had permanent/persistent $\mathrm{AF}$ after the maze procedure and mitral valve repair, the impact of postoperative rhythm on survival and stroke was analyzed separately. As shown in Figures 5 and 6, freedom from cardiovascular-related death and stroke was significantly lower in patients with postoperative AF compared with those in sinus rhythm 1 month after surgery. ${ }^{18}$ Overall, 26 patients had stroke after mitral valve repair. Twenty of those patients were in group BM and had AF both before and after surgery. Of note, $11(11 / 20=55 \%)$ of those patients were not anticoagulated or were inadequately anticoagulated (international normalized ratio $<1.8$ ) with warfarin at the time of their strokes. The importance of maintaining adequate anticoagulation and ensuring compliance with warfarin in patients with $\mathrm{AF}$ deserves reemphasis. ${ }^{19}$

This study was also designed to examine the effect of preoperative rhythm and the maze procedure on late cardiac function. In all groups, LAD decreased after mitral valve repair. However, in patients who did not undergo a maze 
procedure (group $\mathrm{BN}$ ), late recurrent enlargement of LAD was observed, whereas LAD remained small in groups A and BM late after surgery ( $>2$ years). Furthermore, significant improvement of LVDs was observed in group BM when compared with group BN. Thus, left ventricular function may be improved by restoring sinus rhythm after the maze procedure. Although a positive impact of sinus rhythm on cardiac function was observed, we believe these findings are still preliminary because all of the echocardiography indices were load-dependent. Thus, these data may be directly influenced by the alterations in preload and afterload, and the vagaries of medical management. Obviously, further study is necessary to precisely analyze the impact of preoperative and postoperative AF on cardiac function before and after mitral valve repair.

This retrospective multi-institutional study has several limitations. First, the significant number of differences in preoperative background made comparisons difficult among the groups. Patients in sinus rhythm were younger, had better NYHA functional class, and had smaller LAD and LVDs when compared with those with preoperative AF. Thus, it is difficult to precisely blame AF for the decreased survival, reduced freedom from stroke, and inadequate recovery of late cardiac function.

Second, the decision to perform an adjunct maze procedure was primarily according to surgeon preference. Because the Cox maze procedure prolongs cardiopulmonary bypass time, the maze procedure was omitted when patients had complex mitral regurgitation or severe left ventricular dysfunction. However, the cryo-maze technique requires only 20 to 25 minutes of additional aortic crossclamp time, so the adjunct maze procedure is currently performed in the majority of mitral repair cases. ${ }^{20}$ The development of easier "mini-maze" or pulmonary vein isolation techniques with better energy sources may further improve the adaptability of this technique. ${ }^{21}$ Third, although the length of AF before surgery may have a significant impact on preoperative cardiac function, these indices were not examined because the period of AF before surgery was not clear in $40 \%$ of the patients. Fourth, information on left atrial contraction before and after surgery was available in only a few of the patients who underwent maze procedures; thus this information was also not incorporated in this study. ${ }^{22}$

\section{Conclusion}

Preoperative AF was associated with reduced survival and freedom from late stroke after surgery. ${ }^{23}$ The addition of a maze procedure improved late cardiac function, survival, and freedom from late stroke. The development of easier "mini-maze" or pulmonary vein isolation techniques with other energy sources may benefit a significant number of patients with $\mathrm{AF}$ who require extensive and complex mitral valve surgery. ${ }^{24}$

\section{References}

1. Schlant RC. Timing of surgery for patients with nonischemic severe mitral regurgitation. Circulation. 1999;99:338-9.

2. Bonow RO, Carabello B, de Leon AC, Edmunds LH Jr, Fedderly BJ, Freed MD, et al. ACC/AHA Guidelines for the management of patients with valvular heart disease. J Am Coll Cardiol. 1998:1486-588.

3. Triobuilloy CM, Enriquez-Sarano, Schaff HV, Orszulak TA, Bailey KR, Tajik KJ, et al. Impact of preoperative symptoms on survival after surgical correction of organic mitral regurgitation. Circulation. 1999; 99:400-5.

4. Obadia JF, El Farra M, Bastien OH, Lievre M, Martelloni Y, Chassingnolle JF. Outcome of atrial fibrillation after mitral valve repair. J Thorac Cardiovasc Surg. 1997;114:179-85.

5. Chua YL, Schaff HV, Orzulak, Morris JJ. Outcome of mitral valva repair in patients with preoperative atrial fibrillation. Should the maze procedure be combined with mitral valvuloplasty? J Thorac Cardiovasc Surg. 1994;107:408-15.

6. Jessurun ER, van Hemel NM, Kelder JC, Elbers S, de la Riviere AB, Defauw JJAM, et al. Mitral valve surgery and atrial fibrillation: is atrial fibrillation surgery also needed? Eur J Cardiothorac Surg. 2000; 17:530-7.

7. Prasad SM, Maniar HS, Camillo CJ, Schuessler RB, Boineau JP, Sundt $\mathrm{TM}$, et al. The Cox maze III procedure for atrial fibrillation: long-term efficacy in patients undergoing lone versus concomitant procedures. J Thorac Cardiovasc Surg. 2003;126:1822-8.

8. Bando K, Kobayashi J, Kosakai Y, Hirata M, Sasako Y, Nakatani S, et al. Impact of Cox maze procedure on outcome in patients with atrial fibrillation and mitral valve disease. J Thorac Cardiovasc Surg. 2002; 124:575-83.

9. Fuster V, Ryden LE, Asinger RW, Cannom DS, Crijns HJ, Frye RL, et al. ACC/AHA/ESC Guidelines for the management of patients with atrial fibrillation. Eur Heart J. 2001; 22:1852-923.

10. Carpentier A. Cardiac valve surgery-the "French correction." J Thorac Cardiovasc Surg. 1983;86:323-37.

11. David TE, Bos J, Rakowski H. Mitral valve repair by replacement of chorda tendineae with polytetrafluoroethylene sutures. J Thorac Cardiovasc Surg. 1991;101:495-501.

12. Kasegawa H, Kamata S, Hirata S, Kobayashi N, Mannouji E, Ida T, et al. Simple method for determining proper length of artificial chordae in mitral valve repair. Ann Thorac Surg. 1994;57:237-9.

13. Kosakai Y. How I perform the maze procedure. Operative techniques. Thorac Cardiovasc Surg. 2000;5:23-45.

14. Saiki Y, Kasegawa H, Kawase M, Osada H, Ootaki E. Intraoperative TEE during mitral valve repair: does it predict early and late postoperative mitral valve dysfunction? Ann Thorac Surg. 1998;666:1277-81.

15. Rosenbaum PR, Rubin DB. The central role of propensity score in observational studies for causal inference. Biometrika. 1983;70:41-55.

16. Bando K, Kobayashi J, Hirata M, Satoh T, Niwaya K, Tagosari O, et al. Early and late stroke after mitral valve replacement with a mechanical prosthesis: risk factor analysis of a 24 -year experience. $J$ Thorac Cardiovasc Surg. 2003;126:358-64.

17. Lim E, Barlow CW, Hosseinpour AR, Wisbey C, Wilson K, Pidgeon $\mathrm{W}$, et al. Influence of atrial fibrillation on outcome following mitral valve repair. Circulation. 2001:104.(Suppl I) I59-63

18. Benjamin EJ, Levy D, Vaziri SM, D'Agostino RB, Belanger AJ, Wolf PA. Independent risk factors for atrial fibrillation in a population-based cohort. The Framingham Heart Study. JAMA. 1994;271:840-4.

19. Okada Y, Nasu M, Takahashi Y, Handa N, Fujiwara H, Shinkai M, et al. Late results of mitral valve repair for mitral regurgitation. Jpn J Thorac Cardiovasc Surg. 2003;51:282-8.

20. Nakajima H, Kobayashi J, Bando K, Niwaya K, Tagusari O, Sasako Y, et al. The effect of cryo-maze procedure on early and intermediate term outcome in mitral valve disease: case matched study. Circulation. 2002;106(Suppl I):I-46-50 
21. Gillinov AM, Blackstone EH, McCarthy PM. Atrial fibrillation: current surgical options and their assessment. Ann Thorac Surg. 2002;74: 2210-7.

22. Nitta T, Lee R, Schuessler RB, Boineau JP, Cox JL. Radial approach: a new concept in surgical treatment for atrial fibrillation I. Concept, anatomic and physiologic bases and development of a procedure. Ann
Thorac Surg. 1999;67:27-35.

23. Ling LH, Enriquez-Sarano M, Seward JB, Tajik J, Schaff HV, Bailey $\mathrm{KR}$, et al. Clinical outcome of mitral regurgitation due to flail leaflet. N Engl J Med. 1996;335:1417-23.

24. Cox JL. Atrial fibrillation II: rationale for surgical treatment. J Thorac Cardiovasc Surg. 2003;126:1693-9.

Appendix 1. Freedom from reoperation

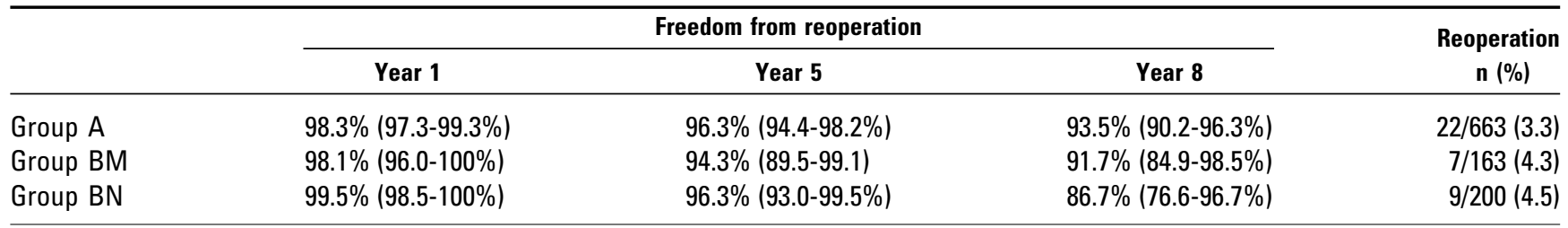

\section{Appendix 2. Mitral regurgitation at last follow-up}

\begin{tabular}{lrrrrr}
\hline & \multicolumn{5}{c}{ MR, $\mathbf{n}(\%)$} \\
\cline { 2 - 6 } & $\mathbf{0}$ & $\mathbf{1}$ & $\mathbf{2}$ & $\mathbf{3}$ & $\mathbf{4}$ \\
\hline Group A $(\mathrm{n}=325)$ & $143(44.0)$ & $130(40.0)$ & $36(11.1)$ & $13(4.0)$ & $3(0.9)$ \\
Group BM $(\mathrm{n}=120)$ & $37(30.8)$ & $61(50.8)$ & $17(14.2)$ & $3(2.5)$ & $2(1.7)$ \\
Group BN $(\mathrm{n}=102)$ & $42(41.2)$ & $30(29.4)$ & $21(20.6)$ & $6(5.9)$ & $3(2.9)$ \\
\hline
\end{tabular}

MR, Mllitral regurgitation.

\section{Appendix 3. Stroke and cardiac-related deaths stratified by postoperative atrial fibrillation and group}

\begin{tabular}{lccrr}
\hline & \multicolumn{2}{c}{ Postoperative AF: No } & \multicolumn{2}{c}{ Postoperative AF: Yes } \\
\cline { 2 - 4 } & Stroke & $\begin{array}{c}\text { Cardiac-related } \\
\text { deaths }\end{array}$ & Stroke & $\begin{array}{c}\text { Cardiac-related } \\
\text { deaths }\end{array}$ \\
\hline Group A $(n=663)$ & $2 / 626(0.3 \%)$ & $5 / 626(0.8 \%)$ & $2 / 37(5.4 \%)$ & $1 / 37(2.7 \%)$ \\
Group BM $(n=163)$ & $0 / 137(0 \%)$ & $1 / 137(0.7 \%)$ & $2 / 26(7.7 \%)$ & $2 / 26(7.7 \%)$ \\
Group BN $(n=200)$ & $0 / 50(0 \%)$ & $0 / 50(0 \%)$ & $20 / 150(13.3 \%)$ & $17 / 150(11.3 \%)$
\end{tabular}

$A F$, Atrial fibrillation.

\section{Discussion}

Dr Kevin Accola (Orlando, Fla). I appreciated the opportunity to review your article beforehand. Dr Bando and his colleagues have extensive database experience relative to mitral surgical procedures. They have contributed other reports to this association regarding mitral valve procedures, associated stroke risk, and atrial arrhythmias. Dr Bando now adds to this very informative retrospective review of the impact on treatment of AF with concomitant mitral valvuloplasty using various forms of the maze procedure.

Basically, Dr Bando's data demonstrate the statistically significant survival improvement at 8 years in patients remaining in sinus rhythm compared with those patients who remain in AF after mitral valvuloplasty, therefore demonstrating a definitive benefit in patients in whom a concomitant maze procedure was performed. Also, freedom from cerebrovascular events was significant at 8 years if the patient was in sinus rhythm preoperatively or if a concomitant maze procedure was performed, compared with those patients who remained in AF regardless of anticoagulation status. Patients who underwent maze procedures demonstrated improved
LVD and subsequent left ventricular function compared with those patients who remained in AF after mitral valvuloplasty.

Dr Bando, I have 4 questions for you. In your article you differentiated between patients in group $B$ as those in preoperative $\mathrm{AF}$ or atrial flutter. How many of these patients were in atrial flutter? Because it is often considered a right-sided phenomenon, did this alter your approach to these patients and does this alter your results?

Dr Bando. Question number 1 related to AF versus flutter. We performed maze procedures in 163 patients; 10 of those were in atrial flutter and 5 of those underwent a right-sided maze procedure, but the remaining 158 patients underwent a full maze procedure.

Dr Accola. Have you evaluated newer technologies and energy sources, and what are your experiences with these? Have you incorporated these into your mitral valvuloplasty procedures?

Dr Bando. In this series, we did not include any of these new devices, but we did have experience with a unipolar radiofrequency catheter in approximately 50 patients. Right now we still have a question about the transmurality of these devices. A good deal of laboratory data is now available to determine the efficacy 
of the new devices, such as from Dr Damiano's laboratory. So our policy is just to sit tight and wait and see which device will be the best fit for us.

However, I totally agree with you. For this type of complex mitral valve repair, the easier mini-maze or pulmonary vein isolation with a better source will certainly increase the adaptability of this technique and further benefit a significant number of patients.

Dr Accola. Dr Bando, in follow-up of the left ventricle dimensional and functional improvement, did you recognize a decrease in LAD, as you have stated, as well as improved atrial contractility? Did you see increasing atrial function when you went back and reevaluated these patients with follow-up echocardiograms?

Dr Bando. There are certain limitations of this large retrospective study, especially, as you pointed out, only part of the patients' data are available in terms of left atrial contractility, and newer techniques, such as the radial approach described by Dr Nitta, certainly will facilitate the contraction of the left atrium. However, we do not have enough information from this retrospective largescale data.

Dr Accola. Last, Dr Bando, regarding anticoagulation, in your article some of the patients who underwent the maze procedure were not anticoagulated postoperatively if they remained in sinus rhythm. Did any of these patients experience cerebrovascular events, and if so, do you think differently now about anticoagulating these patients, considering the numerous left atrial and intra-atrial suture lines present? Would it be safer, possibly, to anticoagulate these patients for a brief period of time postoperatively?

Dr Bando. Because we use rings in most patients, we continue the anticoagulation for 3 months, and with the combined maze procedure, those 3 months are the time we see the various types of arrhythmia. If you do not see any types of arrhythmia, we stop the anticoagulation at 3 months after surgery.
However, we did see 2 patients who underwent a failed maze procedure and had a stroke. At that time there was no left atrial contraction confirmed by serial echocardiography. I think it is important to follow these patients with serial echocardiography whether there is left atrial contraction or not. If there is not, I would recommend to continue anticoagulation.

Dr Eugene H. Blackstone (Cleveland, Ohio). Two concerns. First, I believe that your data are consistent with many other pieces of data that are coming out, so I do not have a concern about that, but I have some concern about an apples and oranges comparison.

Is $\mathrm{AF}$ in your case a marker or a risk factor? Your groups are all very different: You have large ventricles in group B, large atria in group B, and older age in group B. All of these are factors that are related to the outcomes that you have mentioned, and yet there seems to be very little that you have done to try to make these groups comparable.

I think the differences you are seeing are probably much larger than real, and I wonder if you have tried to properly adjust the analysis so we know much more truthfully what the differences are?

Dr Bando. Maybe I should have sent you the article beforehand, Dr Blackstone. I did mention in my presentation that we performed a multivariate analysis, a Cox hazard model using a propensity score. So any possibility of risk factors or predictors such as hypertension, stroke experience, diabetes, or AF was put into the Cox hazard model, and then we analyzed the data. I would not say we simply divided 3 different groups according to whether this is in AF or not, but we did perform the Cox hazard model.

Dr David H. Adams (New York, NY). Can you just tell us about your strategy for the left atrial appendage? Did you ligate it and did you consider a reduction atrioplasty in selected patients?

Dr Bando. That is a very good point. These are 3 different institutional studies, and I would say that the left atrial appendage was ligated and closed in $65 \%$ of patients. However, in some of those different institutions, they do not perform ligation. We would especially not ligate patients in sinus rhythm. 